\title{
Closing the Gap in a Generation: \\ Health Equity Through Action on the Social \\ Determinants of Health. Final Report of the \\ Commission on Social Determinants of Health
}

\begin{abstract}
Commission on Social Determinants of Health (CSDH)
Organização Mundial de Saúde, Genebra, 2008
\end{abstract}

Daniel Gama e Colombo ${ }^{(*)}$

\section{INTRODUÇÃO}

O objetivo deste artigo é oferecer uma breve resenha à obra supramencionada, a partir da perspectiva de um interessado em políticas públicas em saúde que não tenha formação formal na área.

O livro trata do relatório final apresentado pela CSDH, uma Comissão instituída em 2005 pela Organização Mundial de Saúde, para levantar evidências e propor ações para promover equidade em saúde e estimular um movimento global nesse sentido. A CSDH foi chefiada por Michael Mormat e composta por pesquisadores, policy-makers e membros da sociedade civil de diversos países, contando ainda com redes de conhecimento (knowledge networks) e representantes de países parceiros (country partners). Considerando a pluralidade de visões e ideias de seus membros e colaboradores, a Comissão certamente se encontrava em situação privilegiada para elaboração de um documento abrangente, aprofundado e politicamente influente para seus objetivos.

Na qualidade de parceiro desta iniciativa(1), o Brasil foi o primeiro país a instituir sua própria comissão nacional para análise da saúde sob essa

(*) Mestre em Direito Econômico pela Faculdade de Direito da Universidade de São Paulo; especialista em Políticas Públicas e Gestão Governamental do Governo Federal - Escola Nacional de Administração Pública. E-mail: dgcol@ hotmail.com. Recebido em 28.5.09.

(1) "The Commission's formal country partners continue to create momentum for change in different ways (...). Brazil, for instance, launched a National Commission on Social Determinants of Health in March 2006." (COMMISSION ON THE SOCIAL DETERMINANTS OF HEALTH (CSDH). Closing the gap in a generation: health equity through action on the social determinants of health - Final report of the Commission on Social Determinants of Health. Genebra: Organização Mundial de Saúde, 2008). 
abordagem (Comissão Nacional sobre os Determinantes Sociais da Saúde - CNDSS). O Decreto Presidencial de 13.3.2006 instituiu a comissão para um mandato inicial de dois anos. Foram convocadas 17 personalidades, entre intelectuais e ícones da cultura nacional, para compor a comissão (Portaria Ministério da Saúde n. 532/GM de 14.3.2006), que adotou como princípio norteador o seu compromisso com a "equidade", a "evidência" e a "ação". Esta comissão também apresentou um relatório de trabalho sobre determinantes sociais no Brasil em 2008. ${ }^{(2)}$

Considerando a possibilidade de o leitor possuir pouca instrução acerca desses temas, aproveito a oportunidade para apresentar sucintamente os conceitos e ideias básicos que norteiam a obra, quais sejam, os determinantes sociais e as iniquidades em saúde.

Este artigo encontra-se estruturado conforme se segue: na segunda parte abaixo apresento os principais conceitos e modelos teóricos que embasam as análises e ações sobre determinantes sociais; na terceira parte tento resumir e apresentar as ideias do trabalho da CSDH; e, por fim, apresento algumas ideias e reflexões de caráter crítico sobre a obra.

\section{OS DETERMINANTES SOCIAIS EM SAÚDE: CONCEITOS BÁSICOS}

Embora a formulação teórica acerca dos DSS tenha seu principal avanço nas décadas recentes, a utilização dessa abordagem é bem mais antiga, sendo usualmente identificada a partir do século XIX, com o trabalho de cientistas que buscaram relacionar determinadas condições de vida com a proliferação de doenças, a partir da contaminação de alimentos e da água. Ao final do século, bactereologistas forneceram novas formas de pensar a relação saúde-doença, dando origem a um novo paradigma que iria embasar os trabalhos da primeira escola de saúde pública dos Estados Unidos, a Universidade Johns Hopkins ${ }^{(3)}$. A abordagem, todavia, permaneceu não aprofundada durante muito tempo, em especial devido à adoção da medicina e do enfoque biológico como mainstream dos estudos na área de saúde, em detrimento das concepções de saúde pública e de processos sociais como elementos explicativos das enfermidades. ${ }^{(4)}$

A ideia de determinantes sociais ganha força a partir da década de 70 com uma formulação teórica robusta, que tenta identificar problemas de saúde não apenas como decorrência de problemas individuais, mas a partir de

(2) COMISSÃO NACIONAL SOBRE DETERMINANTES SOCIAIS DA SAÚDE (CNDSS). As causas sociais das iniquidades em saúde no Brasil. Rio de Janeiro: Fiocruz, 2008.

(3) Para uma revisão histórica mais detalhada desse processo ver BUSS, Paulo Marchiori; PELLEGRINI FILHO, Alberto. A saúde e seus determinantes sociais. Physis: revista de saúde coletiva, Rio de Janeiro, v. 17, n. 1, jan./abr.2007.

(4) Id. Ibid. 
questões sociais e ambientais que afligem populações ou grupos comunitários inteiros. O ponto central não é negar as especificidades ou a própria responsabilidade dos indivíduos por sua própria saúde, mas reconhecer que as comunidades não podem ser compreendidas apenas como "coleção de indivíduos"(5), havendo padrões de enfermidades ou problemas mais recorrentes em determinados grupos, que podem decorrer do ambiente social e das condições econômicas em que essas comunidades ou grupos estão inseridos.

Embora a ideia por trás dos determinantes sociais seja razoavelmente clara, não há um conceito ou definição única. Tratando-se de um trabalho focado em questões práticas e propostas políticas, fazia sentido que a CSDH adotasse um conceito amplo e não excludente, para abranger o maior número de tópicos ou situações. Conforme o relatório, "a Comissão adota uma perspectiva holística dos determinantes sociais em saúde. (...) Os determinantes estruturais e as condições de vida diária constituem conjuntamente os determinantes sociais em saúde e são responsáveis pela maior parte das iniquidades em saúde entre e dentro dos países". ${ }^{(6)}$

A definição de determinantes sociais pode variar conforme o modelo teórico adotado. Desde a profusão de trabalhos sob essa abordagem foram desenhados alguns modelos para tentar embasar teoricamente a ideia e fornecer elementos norteadores de pesquisas e estudos empíricos. Exemplos são o modelo de camadas ou níveis de Dahlgren e Whitehead (1991) (adotado expressamente pela CNDSS no Brasil) e o modelo de Diderichsen e Hallqvist, adaptado por Diderichsen, Evans e Whitehead, que busca realçar a importância do contexto ou posição social de um indivíduo para a sua exposição a doenças ou situações danosas à saúde ${ }^{(7)}$.

Um segundo conceito que sempre permeia as discussões sobre determinantes sociais é a ideia de equidade (ou iniquidade) em saúde. O fato de que nações ou populações inteiras encontram-se desprovidas de recursos e condições adequadas de vida, de que determinados tratamentos ou medicamentos somente estejam disponíveis para alguns grupos, ou, ainda, de que uma parcela de indivíduos tenha piores condições do que outras em uma mesma sociedade é considerado injusto e um problema social a ser enfren-

(5) SOLAR, Orielle; IRWIN, Alec. Rumo a um modelo conceitual para análise e ação sobre os determinantes sociais de saúde: ensaio para apreciação da Comissão de Determinantes Sociais de Saúde (Rascunho). Genebra: OMS, 2005.

(6) "The Commission takes a holistic view of social determinants of health. (...) Together, the structural determinants and conditions of daily life constitute the social determinants of health and are responsible for a major part of health inequities between and within countries". (COMMISSION ON THE SOCIAL DETERMINANTS OF HEALTH (CSDH). Closing the gap in a generation: health equity through action on the social determinants of health, cit., p. 1, tradução nossa).

(7) Para uma breve revisão e indicação bibliográfica dos modelos, ver SOLAR, Orielle; IRWIN, Alec. op. cit.; Id. A conceptual framework for action on the social determinants of health: Discussion paper for the Commission on Social Determinants of Health. Genebra: WHO, 2007. 
tado. Em um trabalho principalmente conceitual, Whitehead atrela à ideia de iniquidade uma dimensão moral e ética. Nesse viés, iniquidade estaria relacionada a "diferenças que são desnecessárias e evitáveis, mas que também são consideradas injustas". ${ }^{(8)}$ O interessante do trabalho de Whitehead está na precisão que o autor tenta dar ao conceito, excluindo diferenças em saúde decorrentes de condições naturais ou biológicas (como idade ou sexo), ou ainda de opções individuais de estilo de vida (hábitos não saudáveis, prática de atividades perigosas, uso de substâncias danosas à saúde, e não utilização de tratamentos disponíveis por questões religiosas). Nesta percepção, deixa-se de buscar a igualdade de saúde (o que seria impossível), passando a ser almejada a igualdade de oportunidades. ${ }^{(9)}$

Na obra sob análise, a noção de iniquidade surge como uma de suas premissas e principais motivos para a urgente ação dos governos. Sua fundamentação encontra-se principalmente em valores morais e éticos, em especial a percepção de injustiça social. A própria ideia de "close the gap"(10) em uma geração remete à premência de diminuir as iniquidades entre nações. Ao longo do texto, são fornecidos diversos exemplos de situações consideradas injustas e evitáveis, e que podem ser amenizadas ou extintas por meio de políticas públicas e outras intervenções. "Nos casos em que diferenças sistemáticas em saúde podem ser evitadas por meio da ação em nível global e local, tais diferenças são simplesmente injustas. Isto é o que chamamos iniquidade em saúde"(11).

\section{EXTINGUINDO AS DIFERENÇAS EM UMA GERAÇÃO}

\section{Objetivo e estrutura da obra}

O relatório da CSDH baseia-se principalmente em duas premissas. A primeira delas, conforme já mencionado, é a profunda iniquidade em saúde observada. A obra abre destacando um dado a esse respeito, a diferença entre expectativas de vida em alguns países (mais de 80 anos na Suécia e

(8) "The term inequity has a moral and ethical dimension. It refers to differences which are unnecessary and avoidable but, in addition, are also considered unfair and unjust". (WHITEHEAD, Margaret. The concepts and principles of equity in health. Copenhagen: WHO - Regional Office for Europe, 1990. p. 5, tradução nossa).

(9) "Equity in health implies that ideally everyone should have a fair opportunity to attain their full health potential and, more pragmatically, that no one should be disadvantaged from achieving this potential, if it can be avoided". (WHITEHEAD, Margaret. op. cit., p. 7).

(10) Em uma tradução livre, esta expressão significa extinguir as diferenças, fechar o abismo que separa duas ou mais partes.

(11) COMMISSION ON THE SOCIAL DETERMINANTS OF HEALTH (CSDH). Closing the gap in a generation: health equity through action on the social determinants of health, cit., p. 26 . 
Japão, 72 anos no Brasil e menos de 50 em alguns países africanos). A iniquidade é tida como a principal causa de diversos problemas de saúde enfrentados por populações inteiras, e também por pequenos grupos desfavorecidos dentro de países desenvolvidos. É apontada como principal causa da iniquidade a distribuição desigual de poder, renda, bens e serviços. Esta distribuição não é aceita como um fenômeno natural, sendo "o resultado da combinação tóxica de políticas públicas e programas sociais mal desenhados, arranjos econômicos injustos e política ruim".(12) Seria, nesse sentido, obrigação da comunidade global tomar medidas para amenizar as diferenças.

A segunda premissa pode ser descrita como o compromisso com a abordagem de determinantes sociais em saúde. Nega-se a visão tradicional de explicar o cenário de saúde e doença em uma população apenas analisando o setor de assistência à saúde (especialmente assistência médica). É necessária, assim, uma visão mais abrangente, que inclua também atenção às condições de vida das pessoas, como elas nascem, desenvolvem-se, trabalham, relacionam-se e envelhecem. É nesses dados e informações que será possível identificar as iniquidades geradoras de distorções nos indicadores de saúde.

A obra é, assim, extremamente comprometida com o enfoque prático. Seu objetivo é identificar as principais iniquidades nos determinantes sociais em saúde, e propor um conjunto de ações que permita solucionar ou remediar este quadro. Trata-se de uma proposta ambiciosa, na medida em que se propõe solucionar todas as questões - que, conforme será exposto, são inúmeras - no curto espaço de tempo de uma geração. A profunda dificuldade da tarefa não é desconhecida ou menosprezada. Todavia, a Comissão defende a seu favor que o senso de responsabilidade exige que o problema seja atacado tanto imediatamente quanto na qualidade de uma agenda de longo prazo. Como argumentos para comprovar a viabilidade de seu projeto, são apresentados, a todo momento durante a obra, exemplos de políticas públicas e medidas que contribuíram para resolver ou diminuir o problema da iniquidade em diversas partes do mundo.

A estrutura do trabalho segue a compreensão da Comissão sobre como melhorar a equidade. São propostos três princípios de ação, que acabam funcionando como grandes temas, dentro dos quais são inseridos os capítulos ou tópicos mais específicos. Tais princípios são: (i) a melhoria das condições de vida (parte 3), incluindo as condições de gestação e nascimento, o ambiente em que as pessoas vivem, as condições de emprego e trabalho, a proteção social ao longo da vida e a assistência universal em saúde; (ii) uma

(12) "This unequal distribution of health-damaging experiences [...] is the result of a toxic combination of poor social policies and programmes, unfair economic arrangements, and bad politics" (COMMISSION ON THE SOCIAL DETERMINANTS OF HEALTH (CSDH). Closing the gap in a generation: health equity through action on the social determinants of health, cit., p. 1, tradução nossa). 
melhor distribuição de recursos, dinheiro e poder (parte 4); e (iii) a criação de conhecimento e métodos para mensurar os problemas e analisar e avaliar o impacto das ações (parte 5). Além disso, o relatório possui ainda: uma primeira parte, para esclarecer a abordagem de determinantes sociais, e fornecer dados sobre iniquidade em saúde, identificando assim os problemas e indicando soluções; um capítulo para a explicação do quadro teórico e método de coleta e análise de dados (parte 2); e uma última parte (parte 6) dedicada à proposta de construção de um movimento global para solucionar o problema da iniquidade em saúde.

\section{Embasamento teórico e aspectos metodológicos}

O trabalho da CSDH encontra-se embasado por um profundo esforço de aprofundamento teórico, muito embora o tom pragmático da obra não deixe isso transparecer muito. Ao longo da obra são feitas referências a autores consagrados da economia e ciência política como Friedman, Rodrik e Stiglitz, fornecendo sustentação teórica aos argumentos e propostas da Comissão. O trabalho de Sen (1999) aparece com especial relevância, tendo em vista a convergência de suas ideias com a abordagem de determinantes sociais em saúde.

O quadro teórico utilizado pela Comissão foi desenvolvido por Solar e Irwin (2007). Em uma versão anterior deste trabalho (2005), os autores realizam uma revisão da literatura sobre determinantes e de seus modelos teóricos, relacionando a abordagem com a ideia de justiça social de pensadores liberais como Rawls. O resultado final apresenta um modelo "orientado para a ação", cujo objetivo explícito era subsidiar (teoricamente) os trabalhos da $\mathrm{CSDH}$ em identificar os determinantes sociais das iniquidades em saúde a serem estudados e sugerir propostas de ação. ${ }^{(13)}$ Ponto importante a ser destacado é a importância conferida à intersetorialidade e também à participação social e empoderamento de grupos e comunidades desprivilegiadas ou atingidas. ${ }^{(14)}$ Os autores não fazem recomendações de políticas específicas, mas apontam direções e sugerem caminhos a serem considerados na elaboração de políticas. Conforme apontado no relatório, o modelo preocupa-se com as "causas das causas" da iniquidade — os fundamentos e estruturas, em nível global e nacional, que determinam hierarquias e vínculos sociais, gerando assim as condições de vida das pessoas. Esse modelo sugere a ação em duas frentes: as circunstâncias da vida diária — ou seja, condições

(13) SOLAR, Orielle; IRWIN, Alec. Rumo a um modelo conceitual para análise e ação sobre os determinantes sociais de saúde: ensaio para apreciação da Comissão de Determinantes Sociais de Saúde (Rascunho), cit., p. 15.

(14) Id. Ibid., p. 54. 
materiais que determinam diferentes graus de risco à saúde e propensão a grupos de enfermidades; e os determinantes estruturais - compostos pelas características de estratificação social, os valores e normas vigentes em uma dada sociedade, o cenário econômico global e local, e os processos de governança e participação política. ${ }^{(15)}$

Um conceito central para compreender o quadro teórico adotado é o de gradiente social (ou socioeconômico). O gradiente é definido como a relação entre uma dada posição ou nível socioeconômico e os indicadores de saúde da população situada naquele degrau. A ideia parece ser ir além da mera utilização de médias aritméticas de grandes grupos populacionais, compreendendo a existência de uma gradação dos níveis de saúde quando alteramos, ainda que em pequena escala, os indicadores socioeconômicos. Assim, os mais pobres teriam níveis piores de saúde do que aqueles situados na camada social imediatamente superior (ainda que este grupo também seja marginalizado ou possua baixa renda). Igualmente, a população situada no segundo quintil mais alto de distribuição de renda, porquanto possam ter bons índices de saúde, teriam um nível pior do que aqueles situados no primeiro quintil.(16) A perspectiva do gradiente social permite informar como as diversas iniquidades e diferenças na distribuição de riqueza e outros recursos afetam a saúde das pessoas. Conforme Solar e Irwin ${ }^{(17)}$, políticas públicas embasadas na ideia de gradiente social são dotadas de maior complexidade e poderão ser mais dispendiosas, mas uma abordagem comprometida com a equidade deve necessariamente levar este componente em consideração.

A partir do quadro teórico e do conjunto de determinantes sociais selecionados, foram também feitas escolhas quanto ao que deveriam ser consideradas evidências suficientes para subsidiar as recomendações e propostas de políticas públicas feitas pela Comissão. Neste ponto, a CSDH faz um expresso reconhecimento de que seria impossível adotar uma atitude mais rigorosa na seleção de evidências, exigindo, por exemplo, testes aplicados com práticas metodológicas como testes randômicos controlados. Não há, no campo de estudo dos determinantes sociais, pesquisas suficientes a esse respeito, sendo inclusive impossível de serem realizadas em muitos casos. Por esse motivo optou-se por uma definição mais ampla do que constituiria evidência para os trabalhos da Comissão, manifestando ainda a recomendação por mais pesquisas que pudessem trazer contribuições metodológicas qualitativamente melhores a essa abordagem.

(15) COMMISSION ON THE SOCIAL DETERMINANTS OF HEALTH (CSDH). Closing the gap in a generation: health equity through action on the social determinants of health, cit., p. 42.

(16) Id. Ibid., p. 31.

(17) SOLAR, Orielle; IRWIN, Alec. A conceptual framework for action on the social determinants of health: Discussion paper for the Commission on Social Determinants of Health, cit., p. 51. 


\section{Resultados e principais recomendações}

O conjunto de dados, indicadores e recomendações apresentados na obra é não apenas amplo, mas muito diversificado, abrangendo questões como assistência pré-natal, desigualdade de gênero, fluxos migratórios, empregabilidade e ambiente de trabalho, aposentadoria e seguridade social. Em uma tentativa de resumir de forma minimamente apresentável esse amplo leque de assuntos, elaborei a tabela abaixo, que, acredito, mostra as questões mais relevantes do livro. Ressalto que não é uma compilação completa e exata dos tópicos, e que foram necessários ajustes e simplificações.

\begin{tabular}{|c|c|c|c|}
\hline Princípio & Tema & Evidências para ação & Recomendações \\
\hline \multirow{3}{*}{$\begin{array}{l}\text { Melhoria das } \\
\text { condições de } \\
\text { vida }\end{array}$} & $\begin{array}{l}\text { Equidade desde o } \\
\text { início }\end{array}$ & $\begin{array}{l}\text { - Investimento em desen- } \\
\text { volvimento infantil (early } \\
\text { child development) possui } \\
\text { grande potencial de redu- } \\
\text { ção de iniquidades sociais. } \\
\text { Primeiras experiências e } \\
\text { ambiente de recém-nasci- } \\
\text { dos afetam todo o curso } \\
\text { de vida. } \\
\text { - Crianças precisam de am- } \\
\text { biente saudável, educati- } \\
\text { vo e emocionalmente ade- } \\
\text { quado. }\end{array}$ & $\begin{array}{l}\text { - Comprometer-se a e adotar } \\
\text { uma abordagem abrangente } \\
\text { para recém-nascidos, com co- } \\
\text { ordenação entre atores e ór- } \\
\text { gãos, e cobertura para mães } \\
\text { e recém-nascidos, independen- } \\
\text { te de pagamento. } \\
\text { - Ofertar educação primária e } \\
\text { secundária para meninos e } \\
\text { meninas, independente da ca- } \\
\text { pacidade familiar de pagamen- } \\
\text { to. Abolir pagamento para } \\
\text { acesso a escola primária. }\end{array}$ \\
\hline & $\begin{array}{l}\text { Ambientes saudáveis, } \\
\text { pessoas saudáveis }\end{array}$ & $\begin{array}{l}\text { - Em 2007, população ur- } \\
\text { bana superou a rural, com } \\
\text { quase } 1 \text { bilhão de pessoas } \\
\text { vivendo em favelas. } \\
\text { - Urbanização remodela } \\
\text { problemas de saúde, espe- } \\
\text { cialmente para os pobres } \\
\text { de áreas urbanas. Condi- } \\
\text { ções de vida nas cidades } \\
\text { trazem fortes impactos so- } \\
\text { bre a saúde: emissão de } \\
\text { poluentes, acesso a água } \\
\text { e habitação, dependência } \\
\text { de veículos automotores. } \\
\text { - Modelo de urbanização } \\
\text { traz desafios ambientais } \\
\text { (mudança climática). }\end{array}$ & $\begin{array}{l}\text { - Incluir saúde e equidade no } \\
\text { centro da governança e plane- } \\
\text { jamento urbano. } \\
\text { - Assegurar oferta de habitação } \\
\text { por preço acessível; melhoria } \\
\text { de favelas, incluindo fornecimen- } \\
\text { to de água, esgoto, eletricidade } \\
\text { e pavimentação viária. } \\
\text { - Promover equidade entre } \\
\text { áreas urbanas e rurais. } \\
\text { - Compensar as consequências } \\
\text { negativas do crescimento } \\
\text { urbano. } \\
\text { - Assegurar que políticas am- } \\
\text { bientais e de controle climáti- } \\
\text { co considerem a equidade em } \\
\text { saúde. }\end{array}$ \\
\hline & $\begin{array}{l}\text { Emprego e trabalho } \\
\text { justo }\end{array}$ & $\begin{array}{l}\text { - Emprego e trabalho têm } \\
\text { fortes efeitos sobre a equi- } \\
\text { dade em saúde. } \\
\text { - Pesquisas indicam danos } \\
\text { à saúde e maior mortalida- } \\
\text { de em trabalhadores tem- } \\
\text { porários ou em risco de } \\
\text { desemprego. }\end{array}$ & $\begin{array}{l}\text { - Pleno emprego em condições } \\
\text { decentes de trabalho deve se } \\
\text { tornar objetivo central de polí- } \\
\text { ticas nacionais e internacionais. } \\
\text { - Equidade em saúde requer tra- } \\
\text { balho salubre, seguro e bem } \\
\text { remunerado, assim como vida } \\
\text { profissional balanceada e sau- } \\
\text { dável. }\end{array}$ \\
\hline
\end{tabular}




\begin{tabular}{|c|c|c|c|}
\hline Princípio & Tema & Evidências para ação & Recomendações \\
\hline \multirow{3}{*}{$\begin{array}{l}\text { Melhoria das } \\
\text { condições de } \\
\text { vida }\end{array}$} & $\begin{array}{l}\text { Emprego e trabalho } \\
\text { justo }\end{array}$ & $\begin{array}{l}\text { - Condições de trabalho } \\
\text { também afetam equidade } \\
\text { em saúde: stress está re- } \\
\text { lacionado com doenças } \\
\text { cardíacas; e cobrança ex- } \\
\text { cessiva pode gerar doen- } \\
\text { ças físicas e mentais. }\end{array}$ & $\begin{array}{l}\text { - Melhoria das condições ma- } \\
\text { teriais de trabalho, diminuindo } \\
\text { o risco de danos materiais, } \\
\text { stress e ambientes insalubres. }\end{array}$ \\
\hline & $\begin{array}{l}\text { Proteção social ao } \\
\text { longo da vida }\end{array}$ & $\begin{array}{l}\text { - Baixos padrões de vida } \\
\text { são importantes determi- } \\
\text { nantes de iniquidades em } \\
\text { saúde, influenciando traje- } \\
\text { tórias de vida. } \\
\text { - } 4 \text { em } 5 \text { pessoas no mun- } \\
\text { do não estão cobertas por } \\
\text { um sistema básico de se- } \\
\text { guridade social. } \\
\text { - Sistemas de bem-estar } \\
\text { social atacam índices de } \\
\text { pobreza e tendem a melho- } \\
\text { rar a saúde da população, } \\
\text { e seus orçamentos podem } \\
\text { ser mais sustentáveis. }\end{array}$ & $\begin{array}{l}\text { - Estender proteção social a } \\
\text { todas as pessoas, incluindo } \\
\text { trabalhadores em risco de de- } \\
\text { semprego e trabalho domésti- } \\
\text { co, garantindo nível de renda } \\
\text { adequado para vida saudável. } \\
\text { - Aumentar progressivamente } \\
\text { a generosidade dos sistemas } \\
\text { de proteção social. }\end{array}$ \\
\hline & $\begin{array}{l}\text { Assistência universal } \\
\text { em saúde }\end{array}$ & $\begin{array}{l}\text { - Assistência universal é } \\
\text { fundamental para justiça } \\
\text { social. A Comissão consi- } \\
\text { dera a assistência em saú- } \\
\text { de um bem comum, não } \\
\text { uma mercadoria. } \\
\text { - Diversos países ainda } \\
\text { possuem sistema de assis- } \\
\text { tência com iniquidades na } \\
\text { oferta, acesso e uso. } \\
\text { - Gasto público com assis- } \\
\text { tência em saúde possui } \\
\text { viés redistributivo. } \\
\text { - Ocorrência de brain drain, } \\
\text { e deficiência de trabalha- } \\
\text { dores na área da saúde em } \\
\text { alguns países. }\end{array}$ & $\begin{array}{l}\text { - Construção de sistemas de } \\
\text { saúde baseados nos princípios } \\
\text { da equidade, prevenção de doen- } \\
\text { ças e promoção da saúde, } \\
\text { disponibilizando serviços com } \\
\text { cobertura universal, baseados } \\
\text { na assistência em saúde pri- } \\
\text { mária (Primary Health Care). } \\
\text { - Fortalecer liderança do setor } \\
\text { público no financiamento de sis- } \\
\text { temas de saúde, assegurando } \\
\text { acesso universal independente } \\
\text { da capacidade de pagamento. } \\
\text { - Aumentar mão de obra em saú- } \\
\text { de, com capacidade para atuar } \\
\text { sobre os determinantes sociais. } \\
\text { Atuação para reduzir brain drain. }\end{array}$ \\
\hline $\begin{array}{l}\text { Solucionar a } \\
\text { distribuição } \\
\text { desigual de } \\
\text { poder, dinheiro } \\
\text { e recursos }\end{array}$ & \begin{tabular}{|l} 
Equidade em saúde \\
presente em todas as \\
políticas, sistemas e \\
programas
\end{tabular} & $\begin{array}{l}\text { - Cada aspecto do governo } \\
\text { e da economia tem o po- } \\
\text { tencial de afetar a saúde e } \\
\text { a equidade em saúde. Por } \\
\text { isso, coerência entre polí- } \\
\text { ticas públicas setoriais é } \\
\text { essencial. } \\
\text { - Envolvimento da socieda- } \\
\text { de civil é importante: fazer } \\
\text { da saúde e da equidade em } \\
\text { saúde valores intersetoriais } \\
\text { compartilhados em escala } \\
\text { global. }\end{array}$ & $\begin{array}{l}\text { - Incluir saúde e equidade em } \\
\text { saúde como ponto prioritário } \\
\text { dos governos, garantindo que } \\
\text { sejam considerados em todas } \\
\text { as políticas. } \\
\text { - Adotar uma abordagem de } \\
\text { determinantes sociais nas po- } \\
\text { líticas e funções do ministério } \\
\text { da saúde, e apoiar seu papel } \\
\text { de liderança em defender essa } \\
\text { abordagem em outros níveis } \\
\text { de governo. }\end{array}$ \\
\hline
\end{tabular}




\begin{tabular}{|c|c|c|c|}
\hline Princípio & Tema & Evidências para ação & Recomendações \\
\hline \multirow{3}{*}{$\begin{array}{l}\text { Solucionar a } \\
\text { distribuição } \\
\text { desigual de } \\
\text { poder, dinheiro } \\
\text { e recursos }\end{array}$} & $\begin{array}{l}\text { Financiamento } \\
\text { adequado }\end{array}$ & $\begin{array}{l}\text { - Presença de falhas de mer- } \\
\text { cado no fornecimento de } \\
\text { bens e serviços vitais justi- } \\
\text { fica e demanda crescente } \\
\text { presença do setor público. } \\
\text { - Países em desenvolvi- } \\
\text { mento possuem instituições } \\
\text { tributárias pouco desenvol- } \\
\text { vidas, debilitando a capa- } \\
\text { cidade arrecadatória. } \\
\text { - Globalização e interdepen- } \\
\text { dência econômica fortale- } \\
\text { cem argumentos para tri- } \\
\text { butação internacional. } \\
\text { - Ajuda (doação) permane- } \\
\text { ce com baixo volume, ape- } \\
\text { sar de sua importância para } \\
\text { redistribuição de recursos. }\end{array}$ & $\begin{array}{l}\text { - Fortalecer o financiamento } \\
\text { público nacional e internacio- } \\
\text { nal para ação sobre os deter- } \\
\text { minantes sociais em saúde. } \\
\text { - Construir capacidade nacio- } \\
\text { nal para tributação progressi- } \\
\text { va e novos mecanismos de fi- } \\
\text { nanciamento público. } \\
\text { - Honrar a promessa de au- } \\
\text { mentar a ajuda global para } \\
\text { 0.7\% do PIB, e expandir a Ini- } \\
\text { ciativa Multilateral de Perdão } \\
\text { da Dívida (Multilateral Debt } \\
\text { Relief Initiative). }\end{array}$ \\
\hline & $\begin{array}{l}\text { Responsabilidade do } \\
\text { mercado }\end{array}$ & $\begin{array}{l}\text { - Mercado pode trazer be- } \\
\text { nefícios por meio de novas } \\
\text { tecnologias, bens e senviços. } \\
\text { Mas também é responsável } \\
\text { por impactos negativos, } \\
\text { como iniquidades econômi- } \\
\text { cas, poluição ambiental, } \\
\text { condições de trabalho ina- } \\
\text { dequadas e comercialização } \\
\text { e bens não saudáveis. } \\
\text { - Saúde não é mercadoria, } \\
\text { mas uma questão de direi- } \\
\text { tos. Três principais ques- } \\
\text { tões envolvidas: (a) a } \\
\text { comercialização de bens } \\
\text { vitais produz iniquidade, e } \\
\text { por isso a oferta desses } \\
\text { bens deve ser liderada por } \\
\text { órgãos públicos; (b) lide- } \\
\text { rança do setor público na } \\
\text { regulação de bens e servi- } \\
\text { ços danosos à saúde ou à } \\
\text { equidade; e (c) necessi- } \\
\text { dade de institucionalização } \\
\text { de avaliações de impacto de } \\
\text { políticas públicas e regula- } \\
\text { ção de mercado na equida- } \\
\text { de em saúde. } \\
\text { • Iniciativas de responsabi- } \\
\text { lidade social das empresas } \\
\text { têm tido efeitos limitados. }\end{array}$ & $\begin{array}{l}\text { - Institucionalizar a saúde e } \\
\text { equidade em saúde como ques- } \\
\text { tões a serem consideradas em } \\
\text { acordos internacionais e for- } \\
\text { mulação de políticas. } \\
\text { - Fortalecer a representação } \\
\text { de atores da área da saúde } \\
\text { em negociações econômicas } \\
\text { nacionais e internacionais. } \\
\text { - Reforçar o papel central dos } \\
\text { governos na oferta de bens } \\
\text { básicos essenciais à saúde } \\
\text { (água e esgoto), e na regula- } \\
\text { ção de bens com impactos à } \\
\text { saúde (alimentação, álcool e } \\
\text { tabaco). }\end{array}$ \\
\hline & Equidade de gênero & $\begin{array}{l}\text { - Iniquidades de gênero per- } \\
\text { passam todas as socieda- } \\
\text { des. Vieses de gênero na } \\
\text { distribuição de poder, nor- } \\
\text { mas e valores afetam a saú- } \\
\text { de de garotas e mulheres. } \\
\text { - Mulheres são menos re- } \\
\text { muneradas do que homens, }\end{array}$ & $\begin{array}{l}\text { - Aprovação e aplicação de leis } \\
\text { que tornem ilegal a discrimina- } \\
\text { ção por gênero. } \\
\text { • Fortalecer o mainstreaming de } \\
\text { questões de gênero, por inter- } \\
\text { médio de órgãos dedicados a } \\
\text { essa questão na administração } \\
\text { central de governos e organis- } \\
\text { mos internacionais. }\end{array}$ \\
\hline
\end{tabular}




\begin{tabular}{|c|c|c|c|}
\hline Princípio & Tema & Evidências para ação & Recomendações \\
\hline \multirow{3}{*}{$\begin{array}{l}\text { Solucionar a } \\
\text { distribuição } \\
\text { desigual de } \\
\text { poder, dinheiro } \\
\text { e recursos }\end{array}$} & Equidade de gênero & $\begin{array}{l}\text { e têm desvantagens em } \\
\text { educação e oportunidades } \\
\text { de trabalho. } \\
\text { - Mortalidade materna per- } \\
\text { manece alta em diversos } \\
\text { países, e serviços de saú- } \\
\text { de para reprodução são ini- } \\
\text { quamente distribuídos en- } \\
\text { tre e dentro das nações. }\end{array}$ & $\begin{array}{l}\text { - Incluir a contribuição econô- } \\
\text { mica do trabalho doméstico, } \\
\text { assistência e voluntariado nas } \\
\text { contas nacionais. }\end{array}$ \\
\hline & $\begin{array}{l}\text { Empoderamento } \\
\text { político - inclusão e } \\
\text { voz }\end{array}$ & $\begin{array}{l}\text { - Inclusão é importante } \\
\text { para o desenvolvimento, } \\
\text { saúde e bem-estar das po- } \\
\text { pulações e indivíduos. } \\
\text { - Ação da sociedade civil } \\
\text { não pode ser separada da } \\
\text { responsabilidade do Esta- } \\
\text { do em garantir direitos que } \\
\text { assegurem a distribuição } \\
\text { de riqueza material. Abor- } \\
\text { dagens top-down e bottom- } \\
\text {-up são igualmente neces- } \\
\text { sárias e complementares. }\end{array}$ & $\begin{array}{l}\text { - Empoderar grupos sociais por } \\
\text { meio de sua representação nas } \\
\text { decisões políticas. } \\
\text { - Fortalecer sistemas que } \\
\text { protejam direitos humanos, } \\
\text { garantam a identidade (regis- } \\
\text { tro) civil e o apoio a grupos } \\
\text { marginalizados (populações } \\
\text { indígenas). } \\
\text { - Permitir a organização e atua- } \\
\text { ção da sociedade civil de forma } \\
\text { a aumentar a compreensão de } \\
\text { que direitos sociais e políticos } \\
\text { afetam a equidade em saúde. }\end{array}$ \\
\hline & Governança global & $\begin{array}{l}\text { - Diferenças drásticas em } \\
\text { saúde refletem uma situa- } \\
\text { ção de disparidade de po- } \\
\text { der e prosperidade entre as } \\
\text { nações. Os benefícios da } \\
\text { globalização vêm sendo } \\
\text { distribuídos desigualmente. } \\
\text { - Progresso econômico e } \\
\text { em igualdade social atingi- } \\
\text { do entre } 1960 \text { e } 1980 \text { foi } \\
\text { em grande parte afetado } \\
\text { pelo período posterior. }\end{array}$ & $\begin{array}{l}\text { - Tornar a equidade em saúde } \\
\text { um objetivo de desenvolvi- } \\
\text { mento global, e adotar um qua- } \\
\text { dro de determinantes sociais } \\
\text { em saúde. } \\
\text { - ONU, por intermédio da OMS } \\
\text { e do Conselho Econômico e } \\
\text { Social, deve adotar a equida- } \\
\text { de em saúde como meta do } \\
\text { desenvolvimento. } \\
\text { - Fortalecer o papel de lide- } \\
\text { rança da OMS na ação sobre } \\
\text { determinantes sociais. }\end{array}$ \\
\hline $\begin{array}{l}\text { Mensuração e } \\
\text { compreensão } \\
\text { do problema, } \\
\text { análise do } \\
\text { impacto de } \\
\text { ações }\end{array}$ & $\begin{array}{l}\text { Determinantes sociais } \\
\text { em saúde: monitora- } \\
\text { mento, pesquisa e } \\
\text { treinamento }\end{array}$ & $\begin{array}{l}\text { - Rápidas mudanças contem- } \\
\text { porâneas dificultam avalia- } \\
\text { ção de seus impactos so- } \\
\text { bre saúde e equidade. Ação } \\
\text { sobre os determinantes so- } \\
\text { ciais é mais efetiva se em- } \\
\text { basada em sistemas de da- } \\
\text { dos e monitoramento. Estu- } \\
\text { dos mostram que ausência } \\
\text { de dados dificulta aos paí- } \\
\text { ses avançar na agenda de } \\
\text { equidade em saúde. } \\
\text { - Pesquisas atuais são fo- } \\
\text { cadas em aspectos biomé- } \\
\text { dicos, desconsiderando de- } \\
\text { terminantes sociais. }\end{array}$ & $\begin{array}{l}\text { - Assegurar o funcionamento } \\
\text { de sistemas de monitoramen- } \\
\text { to sobre equidade em saúde e } \\
\text { sobre determinantes sociais, } \\
\text { nos níveis local, nacional e } \\
\text { internacional. } \\
\text { - Investir na geração de conhe- } \\
\text { cimento sobre determinantes } \\
\text { sociais e sobre medidas para a } \\
\text { redução das iniquidades. } \\
\text { - Capacity building: Oferecer } \\
\text { treinamento sobre determi- } \\
\text { nantes sociais para atores } \\
\text { envolvidos; e inclusão des- } \\
\text { sa abordagem no currículo de } \\
\text { profissionais de saúde. }\end{array}$ \\
\hline
\end{tabular}

(Fonte: Elaboração própria. Reduções e simplificações de responsabilidade do autor) 


\section{REFLEXÕES E IDEIAS ACERCA DA OBRA}

O relatório final da CSDH pode ser considerado um salto qualitativo nos estudos sobre determinantes sociais da saúde. Isto se dá não tanto pelo modelo teórico apresentado (que ainda deve ser testado e criticado por outros autores), quanto pela enorme compilação de dados e informações sobre políticas públicas e intervenções que afetam os determinantes sociais em larga escala, tanto em níveis mais estruturantes como em assuntos específicos e problemas pontuais. Embora a profundidade de análise e acerto de algumas recomendações possam ser questionados, pode-se dizer que o trabalho dá conta de abordar seriamente um conjunto amplo e complexo de assuntos. A extensão da tabela apresentada acima é um reflexo dessa diversidade.

Um segundo mérito a ser creditado é a posição progressista e ousada assumida pela Comissão em vários dos temas abordados. Mesmo se tratando de discussões polêmicas, foram incorporadas bandeiras e reivindicações que se encontram na agenda contemporânea de movimentos sociais e defensores de direitos humanos. Alguns desses temas são a transversalidade das políticas e ações afirmativas de gênero (gender mainstreaming) e o desenvolvimento de um método de inclusão do trabalho doméstico nas contas nacionais (capítulo 13), o pleno emprego e a universalidade das políticas de proteção social (capítulos 7 e 8), regulação internacional do setor de saúde e reforma do Conselho de Segurança da Organização das Nações Unidas (capítulo 15) e políticas de inclusão e empoderamento político de grupos marginalizados, como as populações indígenas (capítulo 14). A opção da Comissão por enfrentar esses problemas e incluí-los em uma agenda política de recomendações por equidade em saúde é certamente um ponto louvável deste trabalho, na medida em que pode representar um fortalecimento dessas bandeiras e reivindicações.

Entretanto, possivelmente o maior mérito do trabalho - sua ampla abrangência e diversidade de temas - seja também responsável por alguns de seus problemas. Em primeiro lugar, o grande número de temas e as diferentes formas de abordá-los dificulta uma leitura sistemática ou a compreensão da linha de pensamento e método seguido pela Comissão. Os indicadores e dados apresentados são de diversas fontes, e a impressão é que os exemplos são utilizados casuisticamente, sem uma preocupação com a comparação permanente de grupos populacionais fixos (países ou regiões dentro de um país), o que permitiria uma visão mais completa e criticamente comparável sobre a realidade da iniquidade nos territórios escolhidos.

Outro ponto a ser mencionado é que, em geral, cada um dos temas apresentados possui um aprofundado debate específico, com diferentes 
posições e divergências de cunho ideológico ou teórico. Via de regra estes debates não se encontram devidamente explicitados no relatório da $\mathrm{CSDH}$, sendo apresentada apenas a posição defendida pela Comissão, sem as devidas críticas ou alternativas. Exemplos são a defesa da seguridade social universal e do pleno emprego, temas em que as posições defendidas pela Comissão podem ser facilmente questionáveis dependendo da matiz teórica adotada.

Uma questão similar é que raramente são feitas referências mais aprofundadas sobre a viabilidade prática e os reflexos negativos das recomendações. Exemplificativamente, diversas das propostas demandariam um forte aumento do investimento ou gasto público na promoção da equidade, mas não se discute sobre a possibilidade de diminuição de investimentos privados por meio de efeito crowding-out, sobre a gestão e eficiência desses gastos, ou mesmo sobre o impacto deles sobre os orçamentos nacionais e possíveis pressões inflacionárias.

Nesse sentido é que, embora a obra possa ser lida como uma coletânea de temas de interesse para os determinantes sociais e a iniquidade, ela talvez não seja a melhor referência para o aprofundamento da discussão em cada um dos temas.

Há ainda um último questionamento a ser colocado. Considerando o aprofundamento da literatura sobre determinantes sociais, não parece haver dúvidas de que a questão e os impactos sobre a saúde e iniquidade é um aspecto que merece atenção em qualquer discussão sobre políticas públicas, relações econômicas e os diversos âmbitos da vida social, sejam eles os determinantes sociais aqui mencionados ou outros quaisquer. O trabalho da CSDH é importante nesse sentido, e parece deixar esta relação muito clara para um amplo conjunto de fatores. Todavia, não se pode esquecer que cada um desses temas em geral possui também outras questões a serem consideradas, principalmente valores, especificidades históricas e culturais, e hierarquias de diversos níveis e origens. E essas questões não podem ser ignoradas, sob pena das análises permanecerem incompletas, e as recomendações inviáveis. A título de ilustração, a proposta de ampliação do programa de perdão de dívidas de países não desenvolvidos (capítulo 11) demanda, dentre outras coisas, uma consideração profunda sobre o quadro geopolítico e o funcionamento de mercados financeiros internacionais. É, neste sentido, discutível se a perspectiva de determinantes sociais deve ser encarada como o único centro ou principal ponto de discussão desses temas (como parece ser a proposta no relatório da CSDH), ou se, ao contrário, seria mais adequado reconhecer que este é apenas um enfoque a ilustrar e enriquecer debates em geral complexos e não sujeitos a reduções e soluções simples. 


\section{REFERÊNCIAS BIBLIOGRÁFICAS}

BUSS, Paulo Marchiori; PELLEGRINI FILHO, Alberto. A saúde e seus determinantes sociais. Physis: revista de saúde coletiva, Rio de Janeiro, v. 17, n. 1, jan./abr.2007.

COMMISSION ON THE SOCIAL DETERMINANTS OF HEALTH (CSDH). Closing the gap in a generation: health equity through action on the social determinants of health - Final report of the Commission on Social Determinants of Health. Genebra: Organização Mundial de Saúde, 2008.

COMISSÃO NACIONAL SOBRE DETERMINANTES SOCIAIS DA SAÚDE (CNDSS). As causas sociais das iniquidades em saúde no Brasil. Rio de Janeiro: Fiocruz, 2008.

DAHLGREN, Göran; WHITEHEAD, Margaret. Policies and strategies to promote social equity in health. Estcolmo: Institute for Future Studies, 1991.

SOLAR, Orielle; IRWIN, Alec. Rumo a um modelo conceitual para análise e ação sobre os determinantes sociais de saúde: ensaio para apreciação da Comissão de Determinantes Sociais de Saúde (Rascunho). Genebra: OMS, 2005.

A conceptual framework for action on the social determinants of health: Discussion paper for the Commission on Social Determinants of Health. Genebra: WHO, 2007.

WHITEHEAD, Margaret. The concepts and principles of equity in health. Copenhagen: WHO - Regional Office for Europe, 1990. 